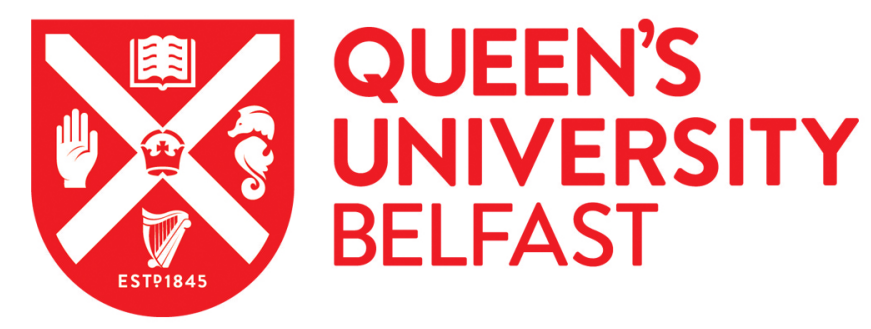

\title{
Improving children's attitudes toward refugees: An evaluation of a school-based multicultural curriculum and an anti-racist intervention
}

Turner, R. N., \& Brown, R. (2008). Improving children's attitudes toward refugees: An evaluation of a schoolbased multicultural curriculum and an anti-racist intervention. Journal of Applied Social Psychology, 38(5), 12951328.

Published in:

Journal of Applied Social Psychology

Document Version:

Peer reviewed version

Queen's University Belfast - Research Portal:

Link to publication record in Queen's University Belfast Research Portal

\footnotetext{
General rights

Copyright for the publications made accessible via the Queen's University Belfast Research Portal is retained by the author(s) and / or other copyright owners and it is a condition of accessing these publications that users recognise and abide by the legal requirements associated with these rights.
}

Take down policy

The Research Portal is Queen's institutional repository that provides access to Queen's research output. Every effort has been made to ensure that content in the Research Portal does not infringe any person's rights, or applicable UK laws. If you discover content in the Research Portal that you believe breaches copyright or violates any law, please contact openaccess@qub.ac.uk. 


\title{
Improving Children's Attitudes Toward Refugees: An Evaluation of a School-Based Multicultural Curriculum and an Anti-Racist Intervention'
}

\author{
RHIANNON N. TURNER ${ }^{2}$ \\ Institute of Psychological Sciences \\ University of Leeds \\ Leeds, United Kingdom
}

\author{
RUPERT BROWN \\ University of Sussex \\ Sussex, United Kingdom
}

\begin{abstract}
We evaluated the impact of the Friendship Project, a program designed to improve elementary school children's attitudes toward refugees. Participants either received 4 weekly lessons based on the program, or they received no lessons. All participants completed attitude measures before and after implementation of the program. Half completed the post-test 1 week after completion of the program, while the other half completed the post-test 7 weeks after its completion. The program led to more positive attitudes toward refugees in the short term, but not in the long term. Moreover, although it did not increase empathy, the program increased the proportion of participants who preferred an acculturation strategy of integration and reduced the number of participants who had conflictual acculturative fit.
\end{abstract}

Because of an increase in civil and international conflict, by the end of 2005 , the world population of refugees, asylum seekers, and internally displaced people had reached 20.8 million, an increase of $6 \%$ over the previous year (United Nations High Commissioner for Refugees [UNHCR], 2006). This large number of refugees represents a significant social problem, not only in terms of finding places where they can live in safety, but also in terms of ensuring harmonious relations between refugees and the communities that host them.

${ }^{1}$ The research reported in this paper was funded by the Economic and Social Research Council. The authors thank Penny Graham and Gill Casebourne at the Kent Refugee Action Network and Dover District Council for providing the Friendship Project resource pack and for locating schools to take part in the research. We also thank Clark McCauley, Ifat Maoz, Richard Crisp, Andrew Baum, and two anonymous reviewers for their helpful advice and comments on an earlier draft of this paper.

${ }^{2}$ Correspondence concerning this article should be addressed to Rhiannon Turner, Institute of Psychological Sciences, University of Leeds, Leeds, LS2 9JT, UK. E-mail: r.n.turner@ leeds.ac.uk or Rupert Brown, Department of Psychology, Pevensey Building, University of Sussex, Falmer, BN1 9QH, UK. E-mail: r.brown@sussex.ac.uk 
We conducted an initial evaluation of the effectiveness of a program in a British educational setting designed to reduce prejudice toward refugees. ${ }^{3}$ While numerous studies have evaluated the effectiveness of interventions that target attitudes toward stable minority groups (e.g., Hill \& Augoustinos, 2001; Vrij, Akehurst, \& Smith, 2003; Walker \& Crogan, 1998), to our knowledge, only one previous study has evaluated the effectiveness of an intervention that targets the attitudes of majority group members toward refugees (Cameron, Rutland, Brown, \& Douch, 2006). Moreover, our study represents the first evaluation of an intervention designed by practitioners and already being used widely in schools as a means of reducing prejudice toward refugees.

Unlike previous studies, which typically have evaluated the impact of the intervention on out-group attitudes, our evaluation includes a broad array of outcome measures, including acculturation strategy, acculturative fit, and empathy toward refugees. In the following sections, we outline the two main perspectives on school-based interventions, highlight the issues facing refugees on their arrival in the UK, describe the program evaluated in the current study and the rationale behind it, and explain how we evaluated its impact.

\section{School-Based Programs to Reduce Prejudice}

The majority of programs used to change intergroup attitudes in educational settings can be broadly divided into two types. Those types are the multicultural curricula approach (Appl, 1996) and the anti-racist approach (Dei, 1996).

\section{Multicultural Curriculum Programs}

Derived from socialization theory, which states that children acquire their attitudes from their family and from peers, multicultural curriculum programs involve teaching children about the culture and lifestyle of minority groups (e.g., Sleeter \& Grant, 1994). If children learn prejudiced attitudes, it would follow that they can also learn positive out-group attitudes via the

\footnotetext{
${ }^{3} \mathrm{~A}$ refugee can be defined as an individual who flees in search of refuge during times of war, oppression, or persecution in his or her country of origin. However, in the UK, a person is only legally a refugee when he or she has been granted refugee status or permission to stay in the UK. Prior to this, refugees who are waiting to hear whether their applications for asylum have been successful are described as asylum seekers. In the present paper, we use the term refugee in our measures because it reflects the aims and objectives of the Friendship Project program, and it is an easier and more familiar term for children. It is also a more inclusive term, describing those who have been granted refugee status, as well as asylum seekers.
} 
same mechanisms (Banks, 1995). This perspective is based on two key assumptions: that prejudice is caused by ignorance, so teaching children about the out-group should reduce prejudice (Appl, 1996); and that children tend to tailor their public behavior, if not their private thoughts (Gavin \& Furman, 1989), to fit acceptable norms. If multicultural materials can be used to establish a norm of tolerance and respect toward an out-group through a process of cognitive dissonance (Festinger, 1957), attitudes should eventually fall in line with behavior, leading to better intergroup relations. However, multicultural curriculum programs frequently fail to reduce prejudice (e.g., Koeller, 1977; Lessing \& Clarke, 1976).

This failure may reflect a problem with the basic premise on which multicultural teaching is based: the idea that children are passive recipients of information. Children are, in fact, thought to actively construct schemas, based on their own observations, which they then use to understand and interpret their social world (Piaget, 1970). When children are presented with attitude-incongruent information that challenges an existing schema, they have a tendency to forget, distort, or ignore that information, leaving the original attitude intact (Neuberg, 1996; Rothbart \& John, 1985). The presentation of multicultural information may also increase the likelihood that children focus on the differences between the in-group and the out-group, rather than the characteristics that they share in common. Therefore, this may contribute to, rather than counteract, a stereotyped knowledge of a group (Bigler, 1999).

\section{Anti-Racist Programs}

An alternative and increasingly popular type of program used to reduce intergroup prejudice involves encouraging children to recognize racism in themselves and in society, and to confront and attempt to reduce this racism (Short \& Carrington, 1996; Walker, 1989). This is often described as the anti-racist approach (Dei, 1996). There is perhaps a stronger theoretical basis for this approach than for the multicultural approach. Programs are typically more interactive, involving group discussion and role-play to explore the concepts of prejudice, discrimination, and tolerance (Spencer, 1998). Piaget (1970) argued that a challenge to one's attitudes results in cognitive conflict, leading to the construction of a more complex understanding of social relations. Moreover, when an individual is forced to face up to his or her prejudiced attitudes and behavior, the subsequent guilt that is felt is likely to result in increased vigilance in the presence of out-group members and, therefore, more positive behavior toward them (Devine, Monteith, Zuwernick, \& Elliot, 1991). 
Anti-racist programs tend to result in greater attitude change than do multicultural programs. Slavin and Madden (1979) found that while the racial attitudes and degree of reported cross-racial friendships among White American teenagers were not significantly affected by reading multiethnic texts or by taking a minority group history course, they were significantly improved by discussions about race. Similarly, Aboud and Fenwick (1999) found that highly prejudiced elementary school children who discussed their intergroup attitudes with an unprejudiced friend subsequently showed lower levels of prejudice. A review of anti-racist teaching programs (McGregor, 1993) showed a moderate positive effect of such programs on out-group attitudes.

Despite these findings, there is inadequate research into the effects of anti-racist programs, a fact that is concerning in light of the frequency with which they are used (Aboud \& Levy, 2000). Anti-racist programs also have the potential to increase, rather than decrease prejudice because insight into the prejudiced attitudes of the in-group may arouse feelings of selfrighteousness rather than guilt, resulting in anger directed toward the target ethnic group (Glasberg \& Aboud, 1981; McGregor, 1993).

\section{Reducing Prejudice Toward Refugees}

In 2005, the UK received 25,155 applications from asylum seekers (National Statistics, 2006), the majority coming from Zimbabwe, Eritrea, Somalia, Afghanistan, and China. Around $20 \%$ of refugees enter the UK via the port of Dover, in South East Kent. While on arrival some of these individuals are quickly dispersed to other areas of the country, many settle temporarily in the Dover area while they await dispersal or for their asylum cases to be heard. Others, including those who have been granted refugee status and unaccompanied minors living in hostels or with host families, settle in Dover on a longer term basis (Kent Refugee Action Network, 2006).

Unfortunately, relations between the local and refugee communities in Dover are far from harmonious. There is little ethnic diversity among the permanent population of Dover $(98.5 \%$ of residents are White, compared to an English average of 90.9\%; Census, 2001), and the region has suffered from economic deprivation and high levels of unemployment in recent years. These circumstances provide a breeding ground for fear and resentment of incoming refugees, who are often perceived as "swamping" the region and taking jobs, benefit payments, and housing away from local residents.

These fears have been exacerbated further by the local and national media. This backdrop of intergroup tensions may adversely affect the attitudes of local children toward refugees. Bigler (1999), for example, noted that 
children are likely to construct theories actively about other groups from their social environment, especially from the media. Given that the children of refugees are enrolled in local elementary schools, to ensure that they integrate into the school with ease, it is essential that attempts are made to dispel negative preconceptions and alleviate prejudice toward them. One way to achieve this might be to teach local children about refugees at school.

In the current study, we evaluate the impact of an intervention being used in schools in Kent to improve attitudes toward refugees. To our knowledge, only one intervention designed to improve attitudes toward refugees has been evaluated previously in an educational setting. Cameron et al. (2006) found that English children who were read stories that portray friendships between majority and refugee children subsequently held more positive attitudes toward refugees. This intervention was designed by social psychologists on the basis of the extended contact hypothesis, the theory that knowing about the cross-group friendships of others is sufficient to reduce prejudice (Wright, Aron, McLaughlin-Volpe, \& Ropp, 1997). Despite its effectiveness, however, it is not a program that is being used currently in schools. In contrast, the program that is evaluated in the current study was designed by practitioners, including teachers and charity workers. The program is used regularly in schools in Kent. Therefore, it is essential for the effectiveness of the program to be evaluated.

\section{The Friendship Project}

The Friendship Project, the program that we evaluate in the current study, was designed by the Kent Refugee Action Network (KRAN), a small voluntary organization dealing with the needs of refugees and asylum seekers in the Kent area. KRAN designed the program in order to encourage positive intergroup relations among the host community and asylum seekers in Dover schools. The program can be defined broadly as coming from an anti-racist perspective, as participants are encouraged to question their existing attitudes through interactive discussion. However, the program also endorses the multicultural approach, as teachers are provided with a series of resources that teach students about the culture, lifestyle, and experiences of refugees in the various countries from which they originate. Here, we describe the objectives of the program, detail the content of the lessons, and outline the resources provided for those teaching the program.

\section{Program Objectives}

The objectives of the Friendship Project program are threefold. First, it aims to develop knowledge: an understanding of what a refugee is; what an 
asylum seeker is; the concept of human equality; and the meaning and possible sources of stereotypes, prejudice, racism, and discrimination. Second, it aims to influence the values of participants: to foster openmindedness and respect for others, and to encourage empathy for refugees. Third, it aims to develop skills: for example, the ability to identify similarities between people of different nationalities; and to detect biases, stereotypes, and egocentric attitudes in the self and in others.

\section{Structured Lessons}

The program consists of four lessons, for which detailed lesson plans are provided. Teachers are encouraged to use these lesson plans in conjunction with the materials provided in the resource pack. Several versions of the program have been designed for different age groups, but the version of the Friendship Project outlined here was designed specifically for 9-11-year-olds.

Lesson 1: Spot the Refugee (Part 1). The lesson begins with a brainstorming session in which students are asked what makes a person a refugee. The teacher stresses that people flee their country of origin out of fear of prosecution because of their political opinions or membership in a particular social group. Students then complete several tasks using Lego ${ }^{\mathrm{TM}}$ figures; for example, identifying the similarities that the $\mathrm{Lego}^{\mathrm{TM}}$ figures share and suggesting an identity for each figure based on their characteristics.

Students are then told that one of the figures is a refugee and that they should guess which one is the refugee and explain how they came up with that choice. They are asked whether any of their reasons match the descriptions written on the blackboard at the start of the lesson. Students are told that this is an important lesson in stereotyping and prejudice, and that harm can be caused by thoughtless name-calling and attribution of negative characteristics to an entire social group. Finally, students are asked to copy the correct definition of a refugee that is provided by the teacher.

Lesson 2: Spot the Refugee (Part 2). To ensure that students remember the previous class, they are asked to recall, through a class discussion, what a refugee is. They are then asked to write answers to the following questions on their own, prior to a class discussion: "What is the one difference between refugees and you and me?"; "What event could have caused a person to flee and leave everything behind?"; "What type of experience might refugees endure during their flight?"; "How would you feel if you were a refugee and had to leave your home, family, and possessions behind and live in another country?"; and "What does the term open mind mean? Why should we keep an open mind and a smile of welcome for refugees?"

Lesson 3: How Does It Feel? (Part 1). Children work in small groups, discussing one of several scenarios. The scenarios are (a) a new student has 
joined their class in the middle of the school year; (b) a child of their own age has been on holiday with his or her family in another country where the language is foreign, and the child has somehow been separated from the other family member; or (c) someone has just heard the bad news that the breadwinner of the family no longer has a job. Led by the teacher, the class shares their findings.

Lesson 4: How Does It Feel? (Part 2). Children look at a poster of a group of Lego ${ }^{\mathrm{TM}}$ people designed by the UNHCR, entitled "How Does It Feel?" where one $\mathrm{Lego}^{\mathrm{TM}}$ person is on his or her own, away from the group. The following questions are used by the teacher as the basis for discussion: (a) "Thinking about the three situations we discussed last lesson, what similar feelings might the lonely Lego person have?"; (b) "What similarities and differences are there between the situation of the lonely Lego figure and the three cases we considered last lesson?"; (c) "What do you think the people who designed this poster are trying to suggest through the way the Lego figures are arranged?"; and (d) "Who do you think is the intended audience of this poster? What attitude toward refugees are the UNHCR encouraging people to adopt in this poster?"

\section{Resource Pack}

Schools wanting to use the program receive a resource pack to aid their teaching. This includes a book of newspaper articles and case studies about refugees from different countries; UNHCR posters that use $\mathrm{Lego}^{\mathrm{TM}}$ figures to show how similar refugees are to the host community and to illustrate the important skills that they can bring to the country; a board game entitled "Your Journey to Safety," which shows some of the experiences refugees may have been through to reach Dover; a list of frequently asked questions and answers about refugees; traditional stories from the home countries of refugees; and basic words in the languages of refugees.

\section{Evaluating the Impact of the Program}

The Friendship Project program has already been implemented in several Dover schools and has received funding from the Home Office (the UK government department responsible for domestic issues) to be produced for schools throughout Dover. But despite the time and resources put into its implementation and the enthusiasm of schools for the program, very little is known about its impact. This is not surprising, given that evaluations of prejudice-reduction programs are relatively scarce. Researchers typically are 
reluctant to carry out such studies because they rarely yield significant effects. In fact, even the impact of so-called successful interventions often appears to be tiny in magnitude or to diminish quickly over time (Bigler, 1999). Although this may reflect inadequacies of the programs themselves, there may also be a methodological explanation.

While interventions designed by social psychologists to reduce prejudice typically are quite focused and involve using a specific task to achieve a particular goal (e.g., Cameron et al., 2006), interventions designed by educational practitioners often utilize a diverse range of methods and tasks in order to achieve attitude change (Duckitt, 1992). This makes it difficult to design and implement evaluations. Given that the Friendship Project is a broad, multifaceted program that combines two approaches (multicultural and antiracist), has a range of objectives and methods, and has little control over how much of the program the teacher actually implements, it is important to have a wide array of measures that might be better able to capture any attitude change among participants. For this reason, we are interested in the effect of the intervention, not only on attitudes toward refugees, but also on preferred acculturation strategy, perceptions of acculturative fit, and empathy toward refugees. Here, we describe each of these additional measures and explain our rationale for including them.

\section{Preferred Acculturation Strategy and Perceived Acculturative Fit}

When immigrants arrive in a new country, they form attitudes regarding whether it is of value to maintain their own cultural identity and characteristics, and whether it is of value to maintain relations with the host society, with combinations of responses on these two issues leading to four acculturation strategies (Berry, 1984). A strategy of assimilation is adopted by those who wish to relinquish their own culture in favor of that of the host society; integration reflects the desire to maintain aspects of their own culture, while also adopting aspects of the host culture; separation is a desire to maintain their own culture solely, while remaining separate from the host society; while marginalization characterizes individuals who neither maintain their own culture nor join the host society. In turn, the host community decides not only which strategy they would prefer immigrants to choose (Bourhis, Moise, Perreault, \& Senecal, 1997), but also which strategy they perceive immigrants to hold (Zagefka \& Brown, 2002).

The preferred acculturation strategy of the host community and the strategy that they perceive immigrants to hold both have far-reaching implications for intergroup relations. A preference among members of the host community for immigrants to integrate rather than assimilate or separate is 
associated with lower levels of prejudice (Zagefka \& Brown, 2002; Zick, Wagner, van Dick, \& Petzel, 2001). Moreover, host community members prefer immigrants who they believe want to assimilate or integrate to those who they think would prefer to separate or marginalize (Van Oudenhoven, Prins, \& Buunk, 1998). There is also evidence that the degree of fit between the strategy preferred by the host community and the strategy preferred by the immigrant community predicts intergroup relations (Bourhis et al., 1997).

Zagefka and Brown (2002) made an alternative proposition, suggesting that the fit between the participant's own strategy preference and the strategy that they perceived the immigrant to prefer might also be influential. They argued that where the participant's own strategy and the perceived immigrant strategy was integration or assimilation, intergroup relations would be harmonious, with mutually positive interethnic attitudes and behaviors. Where there is only partial similarity between the participant's own and the perceived immigrant strategy - for example, when the host group favors assimilation, but perceives immigrants to favor integration - relations will be problematic, with moderate levels of negative intergroup attitudes and behavior. Conflictual relations are expected to occur when members of the host community prefer separation or marginalization, resulting in very high levels of tension between the two groups. In line with these predictions, Zagefka and Brown found that better fit predicted more positive perceptions of intergroup relations.

In the current study, we measure participants' preferred acculturation strategy for refugees, and their perceptions of the acculturation strategy preferred by refugees. If the program meets its objective of increasing participants' knowledge and appreciating similarities between the two groups, it might increase preference for the most adaptive integration strategy and reduce the perceived difference in the strategy choice of the host and refugee communities.

\section{Empathy}

One of the main objectives of the Friendship Project is to encourage empathy toward refugees. The program explicitly aims to generate empathy across the two lessons entitled "How Does It Feel?" In one of the lessons, students imagine children similar to themselves in scenarios analogous to those encountered by refugees and think about how they would feel in this situation. In the following lesson, children think more specifically about how refugees might feel, given their situation.

The decision of the designers of the intervention to try to engender feelings of empathy was sensible, as empathy toward out-group members has 
been shown to reduce prejudice toward those groups (e.g., Batson et al., 1997; Stephan \& Finlay, 1999). If the program succeeds in meeting its objective, participants who complete the program should show increased empathy toward refugees.

\section{Method}

\section{Participants and Design}

Study participants were 87 English elementary school children (43 girls, 44 boys $),{ }^{4}$ ages 9 to 11 years $(M$ age $=9.95$ years, $S D=0.78)$. We chose participants from this age group because the lesson plans were designed specifically for children between these ages. The study had a quasiexperimental pre-test/post-test design. Participants were not assigned randomly to conditions because they had to be taught in their existing classes.

Study participants attended one of three schools in Dover, Kent. In each school, two classes participated: one class completed the Friendship Project program, and the other class acted as a school-level control condition. Participants were 22 Year 5 students (intervention) and 22 Year 5 students (control) in School A; 14 Year 5 students (intervention) and 11 Year 6 students (control) in School B; and 8 Year 5 students (intervention) and 10 Year 6 students (control) in School C. In the UK, Year 5 students are ages 9 and 10, while Year 6 students are ages 10 and 11 .

Although all three schools had recently taught refugees, at the time of the study refugees were only in attendance at Schools A and B. Given that classes in each school were not randomly allocated to condition, the control classes were not true experimental controls, but were included to give us a tentative baseline against which to judge the impact of the intervention. Participants completed dependent measures before and either 1 week after the program (School A) or 7 weeks after the program (Schools B and C). Therefore, the study had a 2 (Condition: intervention vs. control) $\times 2$ (Time: 1 vs. 2 ) $\times 2$ (Post-Test: 1 week vs. 7 weeks) mixed design, with repeated measures on the second factor.

${ }^{4}$ The following presents the distribution of males and females in each class in each school. School A: control class $=8$ girls, 14 boys; intervention class $=16$ girls, 6 boys; School B: control class $=3$ girls, 8 boys; intervention class $=6$ girls, 8 boys; School C: control class $=7$ girls, 3 boys; intervention class $=3$ girls, 5 boys. Although there were more females in the intervention condition $(n=25)$ than in the control condition $(n=18)$, and more males in the control condition $(n=25)$ than in the intervention condition $(n=19)$, we found no differences in participants' initial attitudes toward refugees or in the impact of the intervention as a function of gender. 


\section{Dependent Measures}

Participants completed the same set of measures before and after the implementation of the Friendship Project program. To eliminate the effect of the order in which items were presented in the questionnaire, participants were randomly presented with the questionnaire in one of four different orders. All evaluation questions regarding refugees and the majority of subsequent measures were positively worded, as children often have comprehension difficulties with negatively worded items (Benson \& Hocevar, 1985). Unless stated otherwise, dependent measures used a 5-point Likert-type scale ranging from not at all true to very true. To aid with comprehension, faces with varying expressions were used to depict the degree of agreement, rather than numbers; for example, a frowning face represents not at all true, a neutral face represents the midpoint on the scale, and a smiling face represents very true.

\section{Attitudes Toward Refugees}

Attitude toward refugees was measured by combining the mean score on six items. These items are "I like refugees"; "Refugees are very nice"; "I like to have refugees in my class"; "I like to play with refugees in the playground"; "I am the same as refugees"; and "Refugees like to do the same things I like to do" (Time 1, $\alpha=.89$; Time 2, $\alpha=.89$ ). Responses to these items were coded so that a score of 1 depicts the most negative attitude and a score of 5 depicts the most positive attitude.

\section{Attitudes Toward English and French People}

In order to determine discriminant validity of any change in attitudes toward refugees, we also measured attitudes toward English people (Time 1, $\alpha=.62$; Time 2, $\alpha=.72$ ) and attitudes toward French people (Time 1, $\alpha=.81$; Time $2, \alpha=.75$ ). We used the same items as before, but we replaced the word "refugees" with "English people" or "French people."

French people were included as a target group unrelated to the intervention being evaluated because the relative proximity of France to Dover means that participants are likely to have some knowledge of French people. If the program objective of changing attitudes toward refugees is achieved, attitudes toward refugees should become more positive, but attitudes toward French people and English people should remain unchanged. This prediction may appear at first glance to contradict the argument made by Pettigrew 
(1998), that successful interventions to reduce prejudice should ultimately lead to a reappraisal of in-group attitudes, as individuals come to spend less time with the in-group and are more focused on the out-group. We argue, however, that this is more likely to be a long-term consequence of a successful prejudice-reduction intervention, as individuals put into practice what they have learned from the program; and that in the short term, the attitude change may be more target-specific.

\section{Preferred Acculturation Strategy}

Participants' preferred acculturation strategy (Berry, 1984) was measured using pictorial measures designed by Dias Alexandre, Dupont, Jonas, Zagefka, and Bourhis (2003) to determine children's acculturation strategies. Different degrees of acculturation were presented by having a "refugee shape" (e.g., a triangle) gradually "turn into" the "English shape" (e.g., a square).

The shapes used were counterbalanced: Half of the participants received a questionnaire in which refugee was represented by a triangle and English was represented by a square, while the other half received a questionnaire in which refugee was represented by a square and English was represented by a triangle. Participants were asked which shape they thought refugees should be. They were also asked which shape they thought refugees wanted to be in order to calculate the perceived fit of acculturation strategies (see Appendix).

A score of 1 or 2 on the measure was classified as a preference for separation, a score of 3 was classified as a preference for integration, and a score of 4 or 5 was classified as a preference for assimilation. It is worth noting that these simplified acculturation measures are linear (from assimilation at one extreme to separation at the other, with integration at the midpoint on the scale) rather than two-dimensional, as in Berry's (1984) model. Moreover, they did not assess preference for the strategy of marginalization. We made these changes in order to simplify the concepts involved so that children would be able to understand them.

\section{Perceived Fit of Acculturation Strategies}

To measure participants' perceived fit of acculturation strategies, we coded the data using the same method as Zagefka and Brown (2002). A score of 1 or 2 (indicating a preference for separation) on one or both acculturation measures was classified as conflictual, a score of either 3 (indicating a preference for integration), or 4 or 5 (indicating a preference for assimilation) on 
both measures was classified as consensual, and the remaining combinations of fit were classified as problematic.

\section{Empathy Toward Refugees}

Empathy toward refugees was assessed by taking the mean score from the following two items: "It must be scary for refugees when they arrive in a new country," and "We should be nice to refugees and help them settle in." Strong disagreement with this statement (1) represents low empathy, while strong agreement (5) represents high empathy. The items were significantly correlated (Time 1: $r=.43, p<.001$; Time 2: $r=.34, p<.002$ ).

\section{Procedure}

Prior to the pre-test, a White female researcher told participants that they would be answering questions on what they thought about different groups of people. The researcher was not involved in the subsequent administration of the program. Students who had received parental consent were then instructed to complete the evaluation questionnaire individually without consulting fellow students. They were encouraged to ask, should they experience difficulty in understanding the questions, at which point the classroom teacher and the researcher would offer assistance.

The teacher in each intervention class was given a Friendship Project resource pack and was instructed to teach one lesson each week over a period of 4 weeks. Although the teachers were advised to base their classes on the lesson plans provided in the pack, they were given free rein to administer the contents of the pack in whatever way they felt was appropriate. These instructions were appropriate, as the Friendship Project program is currently being used in Dover schools without a set of explicit instructions. An important aim of the current study is to consider whether the use of the Friendship Project so far has been justified.

The time period between the pre-test and the post-test was 5 weeks at School A (1 week after the end of the intervention) and 11 weeks at Schools $\mathrm{B}$ and $\mathrm{C}$ ( 7 weeks after the end of the intervention), enabling us to compare the short-term versus longer-term impact of the program. The procedure at Time 2 was identical to Time 1, except that a debriefing statement was read to the children, explaining to them what the study was about, in simplified terms. 


\section{Results}

We first conducted analyses to determine the factors influencing participants' attitudes at Time 1 . We then considered the effect of the intervention on each dependent measure as a function of condition, time, and time of post-test.

\section{Preliminary Analyses}

Table 1 shows correlations between each pair of variables at Time 1 and Time 2, while Tables 2 and 3 present participants' mean score for each variable in each class at Time 1 and Time 2, respectively. Before undertaking the main analyses, differences in participants' attitudes toward the English, the French, and refugees at Time 1 were considered a function of condition, order of presentation, gender, age, and school using one-way ANOVA analyses. There were no significant differences in pre-test attitudes toward refugees as a function of condition, $F(1,85)=0.72, p=.40$; order of item presentation, $F(1,86)=1.05, p=.38$; gender, $F(1,85)=2.87, p=.09$; or age, $F(1$, $85)=2.38, p=.08$. There were, however, significant differences as a function of school, $F(2,84)=10.84, p=.001$. Post hoc comparisons reveal that pretest attitudes toward refugees were significantly more positive at School B $(M=3.24)$ than at School A $(M=2.31), t(84)=4.59, p=.001$. Despite this difference, the small samples at Schools B and C mean that we were unable to include school as a factor in subsequent analyses.

\section{Impact of the Friendship Project Program}

For each outcome measure, a three-way 2 (Condition: intervention vs. control) $\times 2$ (Time of Post-Test: 1 week vs. 7 weeks) $\times 2$ (Time: 1 vs. 2 ) mixed-design ANOVA was undertaken, with the last factor as a withinsubjects factor. The results of this analysis for each attitude measure are presented as follows.

\section{Attitudes Toward Refugees}

The analysis reveals a significant effect of Condition $\times$ Time, $F(1$, $83)=8.41, p=.005$. Simple effects tests on this interaction reveal a simple effect of time within the intervention condition, $F(1,43)=12.17, p=.001$, but not within the control condition, $F(1,42)=0.43, p=.84$. Specifically, atti- 


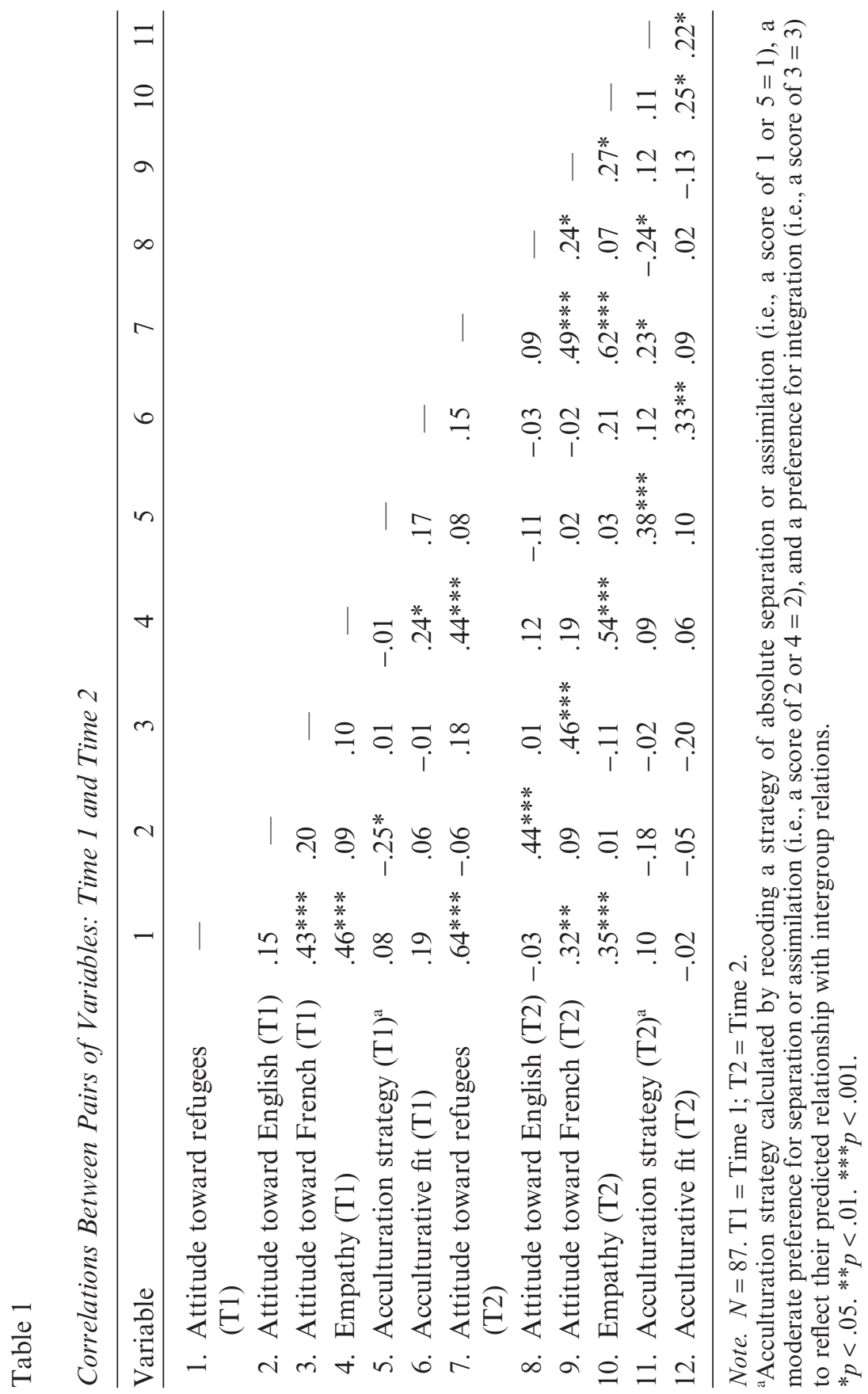




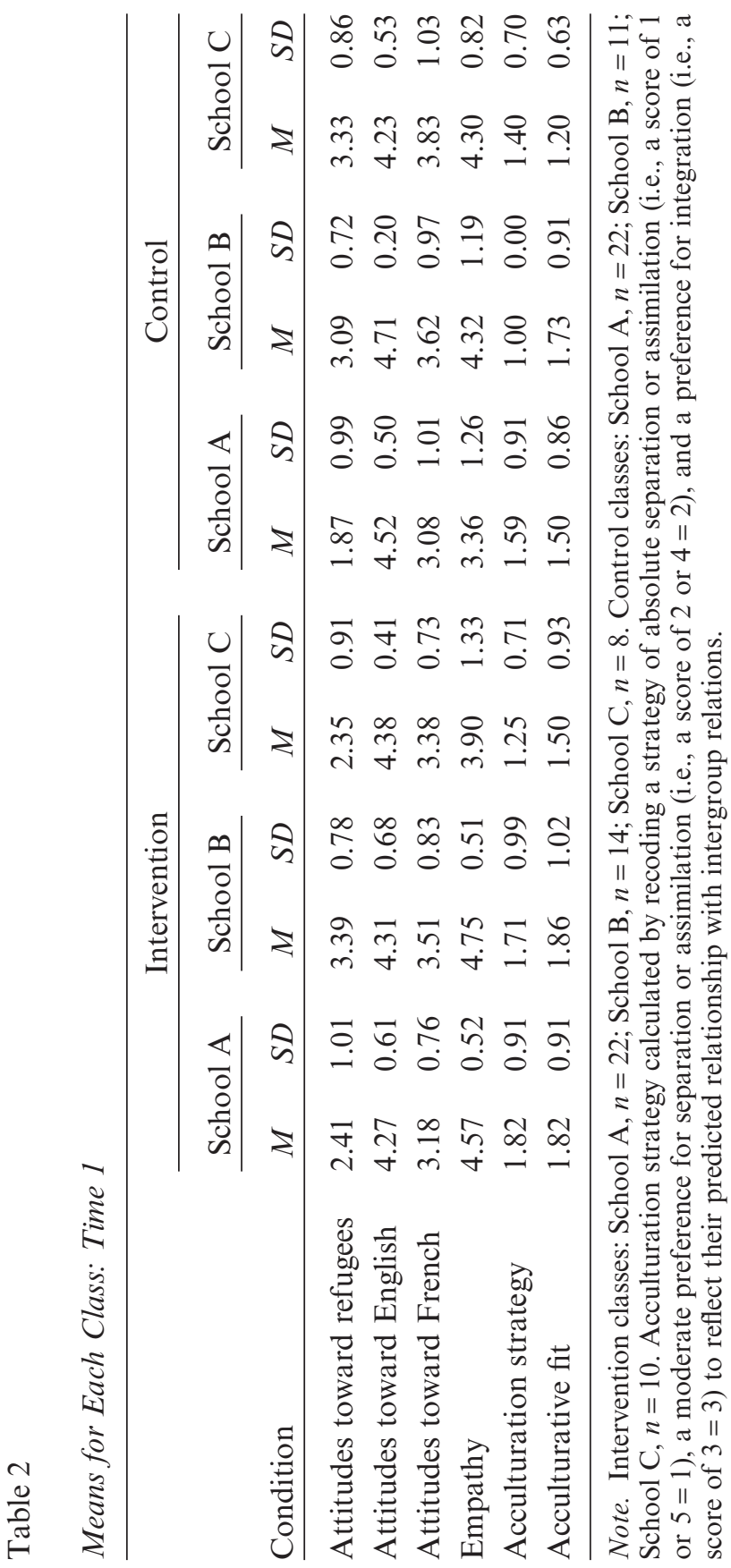




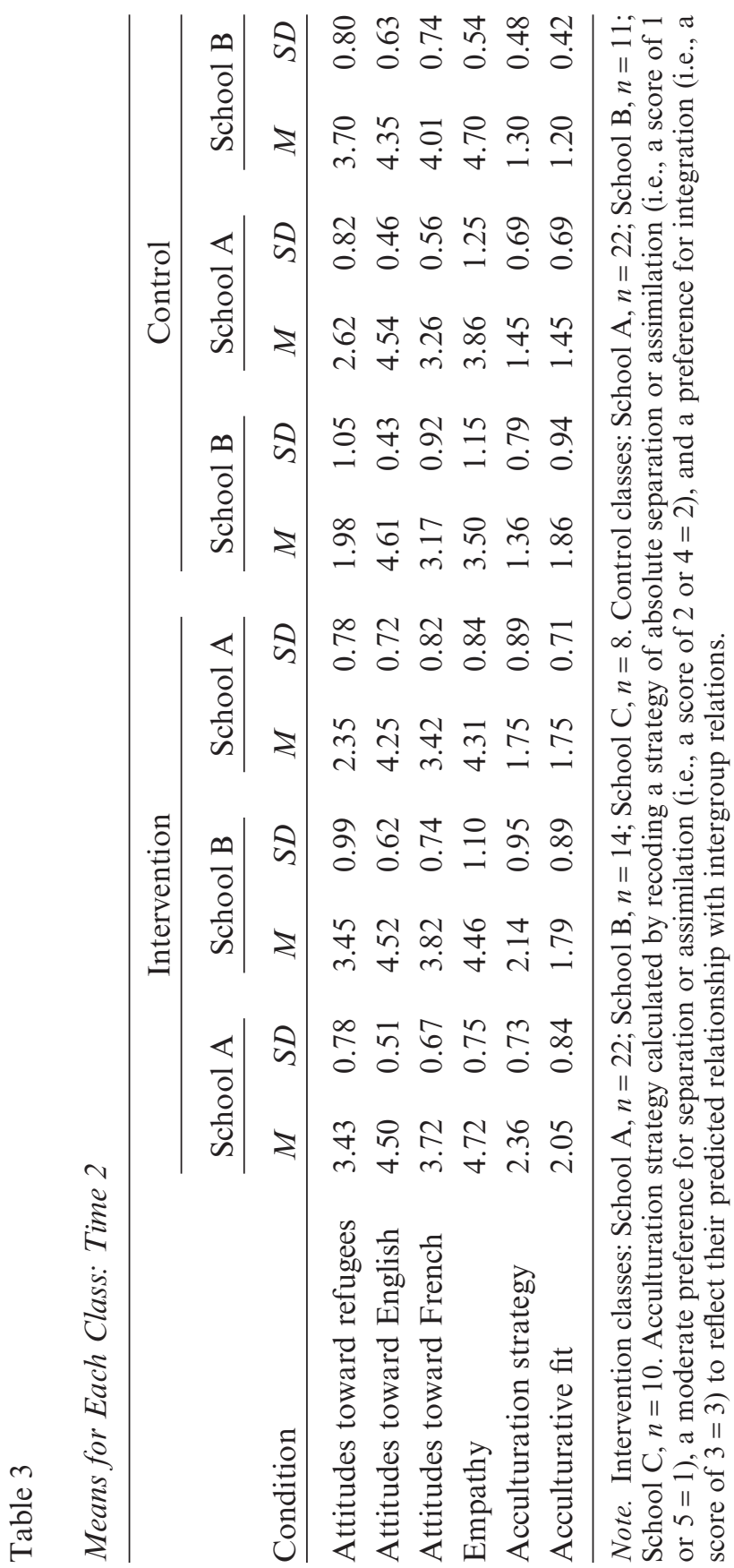


tudes toward refugees changed between the pre-test and post-test in the intervention condition $(M \mathrm{~s}=2.72$ and 3.25 for Time 1 and Time 2, respectively), but did not change between the pre-test and post-test in the control condition $(M \mathrm{~s}=2.52$ and 2.54 for Time 1 and Time 2, respectively). However, the Condition $\times$ Time interaction was qualified by a Condition $\times$ Time $\times$ Time of Post-Test interaction, $F(1,83)=5.19, p=.025$, which indicates that the intervention had a differential impact on participants, depending on the time that the post-test was conducted. To consider these differences, the simple interaction effect of Condition $\times$ Time was tested for participants who completed the short-term post-test and those who completed the long-term post-test.

Short-term post-test. There was a significant Condition $\times$ Time interaction for participants who completed the post-test 1 week after the end of the program, $F(1,42)=11.96, p=.001$. Simple effects tests reveal a simple effect of time within the intervention condition, $F(1,21)=27.94, p=.0005$; but not in the control condition, $F(1,21)=0.41, p=.53$. Specifically, attitudes toward refugees were more positive at Time 2 than at Time 1 in the intervention ( $M \mathrm{~s}=2.42$ and 3.44 for Time 1 and Time 2, respectively), but there was no change in difference in attitudes over time in the control condition ( $M \mathrm{~s}=1.87$ and 1.99 for Time 1 and Time 2, respectively). These findings show that in the short term, the intervention resulted in more positive attitudes toward refugees.

Long term post-test. Despite the apparent short-term benefits of the intervention, there was no significant Condition $\times$ Time interaction for participants who completed the post-test 7 weeks after completion of the program, $F(1,41)=0.22, p=.64$. Attitudes toward refugees did not differ at Time 1 and 2 in the intervention condition $(M \mathrm{~s}=3.01$ and 3.05 for Time 1 and Time 2 , respectively) or in the control condition $(M \mathrm{~s}=3.21$ and 3.13 for Time 1 and Time 2, respectively). Together, these findings suggest that the intervention had only a short-term impact on the attitudes of elementary school children toward refugees (see Figure 1).

\section{Attitudes Toward English and French People}

In order to assess discriminant validity of the intervention, we considered the effect of the intervention on attitudes toward English people and French people. The analysis regarding attitudes toward English people reveals no significant Condition $\times$ Time interaction, $F(2,81)=1.18, p=.28$; or Condition $\times$ Time $\times$ Time of Post-Test interaction, $F(1,83)=0.01, p=.93$. In line with predictions, attitudes toward the in-group were not influenced by the intervention. 

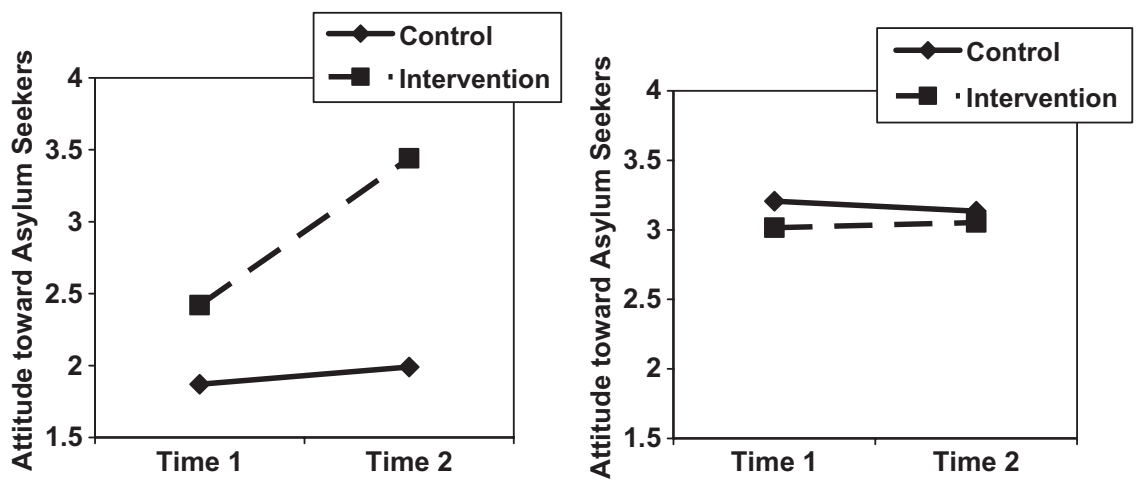

Figure 1. Mean attitude toward asylum seekers as a function of condition and time among participants who completed the post-test (a) 1 week after completion of the program; and (b) 7 weeks after completion of the program.

The analysis regarding attitudes toward French people also reveals no significant Condition $\times$ Time interaction, $F(1,81)=2.61, p=.11$; or Condition $\times$ Time $\times$ Time of Post-Test interaction, $F(1,83)=0.13, p=.72$. Together, these findings confirm that the effects of the program were specific to refugees. They also allow us to discount the possibility that any changes that occurred in attitudes toward refugees were caused by a test-retest effect, rather than by the intervention itself.

\section{Acculturation Strategy Preference}

We computed Pearson's chi-square analyses in order to determine whether the relative distribution of preferred acculturation strategy changed as a function of condition and time. Despite differences in the effect of the intervention on attitudes toward refugees as a function of when the post-test was completed, there were too few participants to conduct separate chi squares for the short-term and long-term post-test groups. Therefore, we considered the effect of the intervention on acculturation strategy across all participants.

In the control condition at Time 1, participants were divided equally in their preference for assimilation or separation, while relatively few participants preferred integration, a strategy distribution that did not change significantly at Time $2, \chi^{2}(4, N=43)=5.40, p=.25$ (see Table 4 ). In the intervention condition at Time 1, participants tended to be in favor of assimilation, while the remainder preferred either integration or separation. At 
Table 4

Distribution of Preferred Acculturation Strategy at Time 1 and 2: Control Condition

\begin{tabular}{lrrrrr}
\hline & \multicolumn{2}{c}{ Time 1} & & \multicolumn{2}{c}{ Time 2 } \\
\cline { 2 - 3 } \cline { 6 - 6 } Strategy & $\%$ & \multicolumn{1}{c}{$N$} & & $\%$ & $N$ \\
\hline Assimilation & 41.9 & 18 & & 34.9 & 15 \\
Integration & 16.2 & 7 & & 11.6 & 5 \\
Separation & 41.9 & 18 & & 53.5 & 23 \\
Total & 100.0 & 43 & & 100.0 & 43 \\
\hline
\end{tabular}

Table 5

Distribution of Preferred Acculturation Strategy at Time 1 and 2: Intervention Condition

\begin{tabular}{lccrrr}
\hline & \multicolumn{2}{c}{ Time 1 } & & \multicolumn{2}{c}{ Time 2 } \\
\cline { 2 - 3 } \cline { 6 - 7 } Strategy & $\%$ & $N$ & & $\%$ & $N$ \\
\hline Assimilation & 40.9 & 18 & & 29.5 & 13 \\
Integration & 29.5 & 13 & & 45.5 & 20 \\
Separation & 29.5 & 13 & & 25.0 & 11 \\
Total & 99.9 & 44 & & 100.0 & 44 \\
\hline
\end{tabular}

Time 2, however, participants' distribution of acculturation strategies changed significantly, $\chi^{2}(4, N=44)=11.89, p=.025$ (see Table 5). Specifically, they showed a reduced preference for assimilation and an increased preference for integration.

We also considered whether acculturation strategy correlated with attitudes toward refugees (e.g., Zagefka \& Brown, 2002; Zick et al., 2001). We recoded a strategy of absolute separation or assimilation (a score of 1 or 5) as 1 , a moderate preference for separation or assimilation (a score of 2 or 4 ) as 2 , and a preference for integration (a score of 3 ) as 3 to reflect their predicted relationship with intergroup relations. We found that although acculturation strategy and attitude were correlated at Time $2(r=.23, p=.035)$, they were not correlated at Time $1(r=.08, p=.47)$. 
Table 6

Distribution of Fit of Own and Perceived Asylum Seeker Acculturation Strategy: Control Condition

\begin{tabular}{lrrrrr}
\hline & \multicolumn{2}{c}{ Time 1 } & & \multicolumn{2}{c}{ Time 2 } \\
\cline { 2 - 3 } \cline { 6 - 6 } Strategy & \multicolumn{1}{c}{$\%$} & & & $\%$ & $N$ \\
\hline Consensual & 20.9 & 9 & & 20.9 & 9 \\
Problematic & 7.0 & 3 & & 18.6 & 8 \\
Conflictual & 72.1 & 31 & & 60.5 & 26 \\
Total & 100.0 & 43 & & 100.0 & 43 \\
\hline
\end{tabular}

\section{Acculturative Fit}

We considered the effect of the intervention on relative distribution of acculturative fit at Time 1 and Time 2 using Pearson's chi-square analyses. In the control condition at Time 1, the majority of participants had conflictual acculturative fit between their own acculturation strategy and the perceived acculturation strategy of refugees. This distribution did not change significantly at Time $2, \chi^{2}(2, N=43)=2.76, p=.25$ (see Table 6 ). In the intervention condition, however, while at Time 1 the majority of participants had conflictual acculturative fit, at Time 2 the number of participants with conflictual fit decreased and the number with problematic fit increased. This change in distribution was significant, $\chi^{2}(2, N=44)=7.93, p=.03$ (see Table 7). We also considered whether acculturative fit was positively correlated with attitude toward refugees, but found that this was not the case (Time $1, r=.19, p=.09$; Time $2, r=.09, p=.42$ ).

\section{Empathy Toward Refugees}

A 2 (Condition: intervention vs. control) $\times 2$ (Time of Post-Test: 1 week vs. 7 weeks) $\times 2$ (Time: 1 vs. 2 ) mixed-design ANOVA does not reveal any significant effect of the intervention on empathy toward refugees. Contrary to predictions, neither the Condition $\times$ Time interaction, $F(1,83)=0.11$, $p=.92$; nor the Condition $\times$ Time $\times$ Time of Post-Test interaction, $F(1$, $83)=0.01, p=.99$, was significant. However, empathy and attitudes toward refugees were correlated with one another at Time $1(r=.46, p=.001)$ and at Time $2(r=.63, p=.001)$, which supports the premise that these factors are 
Table 7

Distribution of Fit of Own and Perceived Asylum Seeker Acculturation Strategy: Intervention Condition

\begin{tabular}{lrrrrr}
\hline & \multicolumn{2}{c}{ Time 1} & & \multicolumn{2}{c}{ Time 2 } \\
\cline { 2 - 3 } \cline { 6 - 6 } Strategy & \multicolumn{1}{c}{$\%$} & & & $\%$ & $N$ \\
\hline Consensual & 34.1 & 15 & & 29.5 & 13 \\
Problematic & 9.1 & 4 & & 31.8 & 14 \\
Conflictual & 56.8 & 25 & & 38.6 & 17 \\
Total & 100.0 & 44 & & 99.9 & 44 \\
\hline
\end{tabular}

related (Batson et al., 1997; Stephan \& Finlay, 1999). ${ }^{5}$ These findings suggest that although empathy may be associated with more positive out-group attitudes, the explicit objective of the Friendship Project program to increase empathy toward refugees was not met.

In sum, the Friendship Project had a short-term effect on students' attitudes toward refugees. Its effects were specific to asylum seekers, as no change in attitudes toward English or French people were observed. The program also changed the acculturation strategy and the fit of this strategy with the perceived strategy of refugees. However, the program did not change participants' empathy toward refugees.

\section{Discussion}

The current study evaluated the impact of the Friendship Project, an intervention designed to generate more positive attitudes toward refugees. The study makes a number of contributions. First, as well as assessing intergroup attitudes, we included an array of additional measures in order to capture any impact of the intervention on empathy, acculturation strategy, and acculturative fit. Empathy was included because of the specific focus on empathy in the program, and acculturation measures were included as they

${ }^{5}$ It might be argued that the second empathy item used here is more strongly related to out-group attitudes than is the first item and, therefore, that the correlation between empathy and attitude is not surprising. However, when we repeated the analyses with the two items separately, they had the same effect as when they were combined into an index. Empathy and attitude were still strongly correlated with one another at both Time 1 and Time 2 . 
are specifically important in the context of host-community/immigrantcommunity relations. Given the breadth and variety of objectives and tasks included in the Friendship Project program, inclusion of these measures increased the likelihood that any changes as a consequence of the intervention would be captured.

Second, to our knowledge, this is the first evaluation of a program being used in schools that is aimed at majority relations with refugees, rather than relations with a stable minority group (e.g., Hill \& Augoustinos, 2001; Katz $\&$ Zalk, 1978). Third, in contrast to many intervention evaluations, we were able to assess the discriminant validity of the program by including measures of attitudes toward groups toward whom attitudes were not expected to change as a result of the intervention. Finally, it is one of few evaluations that considers the long-term as well as the short-term impact of prejudicereduction interventions (Bigler, 1999), although methodological concerns mean that we can only draw tentative conclusions about how the lasting impact of the intervention.

In the following sections, we discuss the impact of the intervention and elucidate some of the limitations of the Friendship Project program and its evaluation. Finally, we highlight some practical implications of this research.

\section{Impact of the Friendship Project Program}

From the current findings, we can tentatively conclude that the Friendship Project program had a positive short-term impact on students' attitudes toward refugees. While this change was small in magnitude, attitudes crossed the midpoint of the scale, from slightly negative to slightly positive attitudes toward asylum seekers. Interventions are often criticized for failing to produce meaningful change (e.g., Bigler, 1999), but we believe that this reflects a meaningful change in attitude.

Attitudes toward French and English people remained unchanged, demonstrating that the program had discriminant validity. It did not, however, have a long-term positive impact on students' attitudes toward refugees: 7 weeks after completion of the intervention, attitudes were the same as they had been at the time of the pre-test. In sum, the Friendship Project appears to have an impact - albeit relatively small — that last weeks, but not months. We acknowledge that because participants were not randomly assigned to conditions, the time of the post-test is confounded by the school attended by participants, something that we discuss in more detail later. However, our interpretation is consistent with previous evaluations of prejudice-reduction interventions that typically show that positive attitude change resulting from an intervention quickly weakens or disappears (Bigler, 1999; Hill \& Augoustinos, 2001; Katz \& Zalk, 1978). 
The Friendship Project program had an impact on participants' preferred acculturation strategy. The majority of participants in the control condition had a consistent preference for separation or assimilation, while the majority of participants in the intervention condition also had a preference for assimilation at Time 1. A host-community preference for separation or assimilation is problematic for intergroup relations, as both are associated with higher levels of prejudice and more negative perceptions of intergroup relations (Zagefka \& Brown, 2002; Zick et al., 2001). Following the Friendship Project program, however, participants in the intervention condition showed a decreased preference for assimilation and an increased preference for integration; that is, they were more likely to want refugees to have contact with the host community and to maintain ties to their culture of origin. These findings have positive implications for intergroup relations, as integration is associated with the opposite effects to assimilation and separation: more positive out-group attitudes and more positive perceptions of intergroup relations (Zagefka \& Brown, 2002; Zick et al., 2001).

The Friendship Project program also had an impact on students' acculturative fit, the degree of correspondence between their own acculturation preference, and what they perceived to be the acculturation preference of refugees. The majority of participants in the control condition at Time 1 and 2 , and in the intervention condition at Time 1 had conflictual acculturative fit; that is, they had a preference for separation or perceived refugees to have a desire for separation. This poor acculturative fit has previously been linked to higher levels of intergroup bias and poorer perceptions of intergroup relations (Zagefka \& Brown, 2002). At Time 2 in the intervention condition, however, fewer participants had conflictual fit, and more had problematic fit. Clearly, this is not ideal: Those with problematic fit prefer assimilation, but think refugees prefer integration, or vice versa. However, these strategies at least reflect a desire for cross-community contact and, therefore, are a step in the right direction.

Together, these findings confirm that the intervention not only influenced participants' general attitudes toward refugees, but also affected their more specific views regarding relations with immigrants when the immigrants arrive in the host community. Unfortunately, we cannot determine whether these changes occurred in both the short term and the long term because of the small sample size. Given that the overall effect of the intervention on attitudes toward refugees was qualified by the time the post-test was taken, it is possible that the same is true for the acculturation measures. However, what is important here is that the Friendship Project program did have a positive impact on both preferred acculturation strategy and acculturative fit, both of which have positive implications for host-community/refugee relations. 
We acknowledge that we did not find acculturation strategy or acculturative fit to be associated with attitudes toward refugees in the current study. However, it may be that the positive effect of acculturation strategy on attitudes is not immediate and, therefore, was not captured in the current study. Future research is necessary to confirm the conditions under which acculturation strategy and out-group attitude are related.

\section{Limitations of the Friendship Project Program}

The effect of the Friendship Project program on acculturation measures is promising, but it is important to note a number of limitations. First, these measures did not correspond directly with Berry's (1984) typology of acculturation strategies. Berry proposed that immigrants could adopt one of four strategies, depending on the extent to which they wanted to maintain ties with the immigrant community and the extent to which they wanted to develop ties with the host community. In contrast, we used a pictorial linear scale in which participants could choose a strategy of assimilation on one side, integration in the middle, or separation on the other side. We chose to use this measure because pilot research has revealed that elementary school children have difficulty understanding Berry's two-dimensional typology.

Second, we coded only participants who chose the midpoint on the acculturation scale as preferring a strategy of integration. However, one could argue that participants who scored on either side of the midpoint also show a preference (albeit to a lesser extent) for integration. Therefore, our figures may have underestimated the extent to which children are in favor of integration. What remains important, however, is that the children showed an increased preference for integration over time as a consequence of the intervention.

Third, the acculturation strategies proposed by Berry (1984) and adapted for the purposes of the current study were designed to reflect the issues facing immigrants, rather than refugees. Many immigrants have lived in the host country for generations and hold full citizenship. In contrast, however, most refugees have only recently arrived in the country. They often face acute discrimination from members of the host community, who perceive them to be a threat to local resources (e.g., housing, benefits). Moreover, because of their legal status, they are often unable to participate fully in the community. For example, they are typically not allowed to work. As a result, they are more likely than immigrants to be on the margins of the host society, severely limiting the acculturation strategies that they can chose to use. It is important that future research of this kind takes into account the unique status of refugees. 
The Friendship Project program had no effect on empathy toward refugees. This is somewhat surprising, given that generating empathy is a key objective of the program. Indeed, two of the four lessons specifically focus on tasks that involve putting oneself in the shoes of refugees and imagining how it might feel to be in that position. The complexity of the role of empathy in intergroup relations might help to explain why the program did not have the expected impact.

Empathy is multifaceted and includes both positive and negative components (Davis, 1994). While positive reactions to attempts to elicit empathy may include concern, compassion, and a desire to behave altruistically (Batson et al., 1997), negative reactions to the plight of refugees may include guilt, shame, anxiety, threat, or revulsion. People may deal with these unpleasant emotions by avoiding refugees altogether or by blaming refugees for the situation in which they find themselves (Coller \& Resick, 1987). It may be that the Friendship Project program's attempts to generate empathy failed to produce the positive responses that were desired. A second possible explanation for the lack of impact on empathy might be that the two-item measure that was used failed to capture the type of empathy generated by the program. Future evaluations of interventions should ensure that comprehensive measures are included that are able to capture adequately the fundamental objectives of the program.

The modest and short-term impact of the Friendship Project program might be explained in part by limitations specific to this program and to the context in which it was conducted. Participants who took part in the Friendship Project live in a region where they are have been exposed on a long-term basis to hostile community attitudes toward refugees as well as media coverage of refugees that is typically extremely negative. However, the Friendship Project program lasted for just four classes over a period of only 4 weeks. Therefore, the brief period of the intervention was unlikely to have been able to counteract the ongoing impact of such an environment.

The Friendship Project program shares a problem that is common to the majority of school-based prejudice-reduction interventions: a lack of input from experts in prejudice reduction. Given the difficulty of field-based research, academics are often reluctant to spend time designing interventions that will be difficult to put together and to evaluate successfully. As a result, educational professionals use their intuition and creative abilities to create interventions that they believe may reduce prejudice (Aboud \& Levy, 2000). While admirable, these interventions may be less effective than if they had theoretical input from social psychologists. Interventions like the Friendship Project are, for example, partly based on the assumption that the acquisition of knowledge by presenting information that is counter to one's current beliefs and expectations will reduce prejudice. However, social psychological 
research has shown that stereotyped perceptions of out-groups are resistant to attitude change, as we have a tendency to maintain our attitudes by challenging, distorting, or ignoring information that is not consistent with our attitude schema (Neuberg, 1996; Rothbart \& John, 1985).

The difference in impact between interventions designed by social psychologists and those designed by practitioners is illustrated clearly when the current research is compared to the intervention designed and evaluated by Cameron et al. (2006) to reduce prejudice among schoolchildren toward refugees. Cameron et al. found that learning about the cross-group friendships of others had a strong positive impact on out-group attitudes, although it should be noted that the long-term impact of the intervention was not assessed. This concept of extended contact, which itself has been demonstrated in a number of studies (Turner, Hewstone, Voci, \& Vonofakou, in press; Wright et al., 1997), is based on the intergroup contact hypothesis (Allport, 1954): the idea that positive contact between members of different groups can reduce intergroup prejudice. This theory has received extensive empirical support (Pettigrew \& Tropp, 2006; Turner, Hewstone, Voci, Paolini, \& Christ, 2007).

What interventions based on intergroup contact do that interventions designed by practitioners typically do not is to generate positive, affective, emotional responses to the out-group, rather than simply changing what students know about the out-group. Generating affective ties in this way seems to be critical in generating strong and lasting attitude change (Pettigrew, 1998). However, despite the clear benefits of interventions based on social psychological principles, at present they rarely are adopted by school prejudice-reduction programs. It is essential, therefore, that the prejudicereduction programs that are currently being used by practitioners in schools adopt these principles if they are to be effective.

\section{Limitations of the Present Research}

Although we have overcome some of the shortcomings of previous intervention evaluations - for example, by using a range of outcome measures, comparing a short-term and long-term post-test, and having a school-level control condition in each school - constraints of the field setting mean that the study had some inevitable methodological limitations. First, the eclectic nature of the Friendship Project program made it very difficult to evaluate. The program combines multicultural and anti-racist elements, making it impossible to tease apart the unique impact of each approach. Moreover, because the anti-racist aspect of the program involves telling children about 
the problem of prejudice, one might argue that change on the attitude measure simply reflects adherence to a norm of not being prejudiced, rather than true attitude change.

However, we did try to circumvent this problem in two ways. Dependent measures were administered by a researcher who had no role in administering the intervention in order to reduce the likelihood that children would respond in a socially desirable manner. We also included several less direct outcome measures. On the acculturation measures, for example, it would not have been so easy for children to determine which response was best associated with an anti-racist norm, yet the program had an impact nevertheless. Future research evaluating prejudice-reduction programs that have a variety of elements should be careful to include a range of outcome measures, from straightforward self-reported attitude measures to measures of implicit outgroup attitudes (e.g., Implicit Association Test; Greenwald, McGhee, \& Schwartz 1998).

Second, as no explicit instructions were given regarding how the intervention should be implemented, it is inevitable that the Friendship Project resource pack was implemented by the teachers in different ways. This was intentional, as we wanted to investigate whether the intervention, as it is currently used, is effective. However, this makes it difficult to pinpoint the exact causes of the relative success or failure of the intervention. It also means that we are unable to conclude that the intervention would be equally effective when used by other teachers or in other schools. A much broader intervention study, including multiple schools, would be necessary in order to draw such a conclusion.

Third, we were unable to assign participants randomly to intervention and control classes. For practical reasons, the program had to be taught within the existing class groups. The small number of participants at each individual school also meant that we had to draw participants from three different schools. While one possible interpretation of the significant effect of the intervention in School A and the null effect of the intervention at Schools B and $\mathrm{C}$ is the short-term versus long-term nature of the pre-test, these schools and their students may differ in a number of ways (e.g., students' socioeconomic status, classroom teachers' political leanings and teaching styles).

The different degrees of intergroup contact experienced across the three schools also may have had an impact. Although all three schools had refugees in attendance at some point, at the time of the study, only Schools A and B did. In the short-term post-test sample, therefore, children had the opportunity to put the lessons they had learned into practice with their refugee classmates. In the long-term post-test sample, on the other hand, only about half of the participants attended a school where they had the chance to interact with refugees. 
Another notable difference is that in the long-term post-test group, attitudes were more positive at Time 1 than in the short-term post-test group. One might argue, therefore, that there was a ceiling effect in the long-term post-test condition; that is, there may have been little scope for attitude improvement. We believe, however, that this is unlikely to be the case. Among participants who received the long-term post-test, the mean attitude was only slightly more positive than the neutral midpoint. In sum, there may be alternative explanations for the differential outcomes across schools that we cannot rule out conclusively. Ideally, therefore, all schools should complete a short-term and a long-term post-test.

\section{Practical Recommendations}

Despite the limitations of the Friendship Project program, it did have an impact on attitudes toward refugees in the short term, and led to positive changes in preferred acculturation strategy and perceived acculturative fit. The main problem with the program is that its impact is modest and does not appear to be long lasting. What is important, however, is that programs to reduce prejudice are being used in schools, despite their difficulties.

The next step is to improve the impact of the Friendship Project and other similar prejudice-reduction programs, something that might be achieved by taking the following steps. First, programs should be integrated into lessons in every year of schooling, rather than being used for a short period of time. Second, where possible, the programs should be followed or combined with structured cooperative intergroup contact (Allport, 1954) with the target group, especially contact that encourages the development of cross-group friendships (Paolini, Hewstone, Cairns, \& Voci, 2004; Pettigrew, 1997; Turner, Hewstone, \& Voci, 2007). This is particularly important, as direct experience produces stronger and longer lasting attitudes than does indirect experience (Fazio, Powell, \& Herr, 1983; Stangor, Sullivan, \& Ford, 1991). Following up a class-based intervention with intergroup contact should ensure that any positive changes in attitude as a result of the intervention are reinforced by direct experience with the target group, leading to longer lasting attitude change.

Third, interventions to reduce prejudice in school settings should incorporate elements of prejudice-reduction strategies that have been tested by social psychologists in controlled settings; for example, emphasizing positive personal characteristics of out-group members while keeping in mind their group membership (Brown \& Hewstone, 2005), getting participants to think about commonalities held by the host community and refugees to create the perception of a common in-group identity (Gaertner \& Dovidio, 2000), and 
getting participants to think about the positive intergroup contact experiences of others (Cameron et al., 2006; Wright et al., 1997; Turner et al., in press). We acknowledge, however, that teachers may be better placed than psychologists to know how their students comprehend and respond to new information. Rather than moving the design of interventions entirely into the hands of psychologists, teachers and psychologists should combine their various expertise to produce a more effective intervention.

Finally, where the target of a prejudice-reduction intervention is refugees or recent immigrants, the current findings highlight the merit of including a broad range of outcome measures, particularly measures of acculturation strategy and acculturative fit. Given that both measures have been shown in previous studies to predict more positive intergroup relations, interventions should make explicit efforts to encourage a preference for integration and consensual acculturative fit; for example, by emphasizing the importance of simultaneously allowing immigrants to maintain their own culture while having contact with the host community and by showing that immigrants have a desire to integrate.

\section{References}

Aboud, F. E., \& Fenwick, V. (1999). Evaluating school-based interventions to reduce prejudice in preadolescents. Journal of Social Issues, 55, 767-786.

Aboud, F. E., \& Levy, S. R. (2000). Interventions to reduce prejudice and discrimination in children and adolescents. In S. Oskamp (Ed.), Reducing prejudice and discrimination: The Claremont Symposium on Applied Social Psychology (pp. 269-293). Claremont, CA: Claremont Graduate School. Allport, G. W. (1954). The nature of prejudice. Reading, MA: AddisonWesley.

Appl, D. J. (1996). Recognizing diversity in the early childhood classroom: Getting started. Teaching Exceptional Children, 28, 22-25.

Banks, J. A. (1995). Multicultural education: Its effects on students' racial and gender role attitudes. In J. A. Banks \& C. M. Banks (Eds.), Handbook of research on multicultural education (pp. 617-727). New York: Macmillan.

Batson, C. D., Polycarpou, M. P., Harmon-Jones, E., Imhoff, H. J., Mitchener, E. C., Bednar, L. L., et al. (1997). Empathy and attitudes: Can feelings for a member of a stigmatized group improve feelings toward the group? Journal of Personality and Social Psychology, 72, 105-118.

Benson, J., \& Hocevar, D. (1985). The impact of item phrasing on the validity of attitude scales for elementary school children. Journal of Educational Measurement, 22, 231-240.

Berry, J. W. (1984). Cultural relations in plural societies: Alternatives to segregation and their sociopsychological implications. In N. Miller \& 
M. B. Brewer (Eds.), Groups in contact: The psychology of desegregation (pp. 11-29). Orlando, FL: Academic Press.

Bigler, R. S. (1999). The use of multicultural curricula and materials to counter racism in children. Journal of Social Issues, 55, 687-705.

Bourhis, R. Y., Moise, L. C., Perreault, S., \& Senecal, S. (1997). Towards an interactive acculturation model: A social psychological approach. International Journal of Psychology, 32, 369-389.

Brown, R., \& Hewstone, H. (2005). An integrative theory of intergroup contact. In M. P. Zanna (Ed.), Advances in experimental social psychology (Vol. 37, pp. 255-343). San Diego, CA: Academic Press.

Cameron, L., Rutland, A., Brown, R., \& Douch, R. (2006). Changing children's intergroup attitudes towards refugees: Testing different models of extended contact. Child Development, 77, 1208-1219.

Census. (2001). Neighbourhood statistics. Retrieved August 6, 2006, from www.neighbourhood.statistics.gov.uk

Coller, S. A., \& Resick, P. A. (1987). Women's attributions of responsibility for date rape: The influence of empathy and sex-role stereotyping. Violence and Victims, 2, 115-125.

Davis, M. H. (1994). Empathy: A social psychological approach. Bolder, CO: Westview.

Dei, G. J. S. (1996). Anti-racism education: Theory and practice. Halifax, Nova Scotia, Canada: Fernwood.

Devine, P. G., Monteith, M. J., Zuwernick, J. R., \& Elliot, A. J. (1991). Prejudice with and without compunction. Journal of Personality and Social Psychology, 60, 817-830.

Dias Alexandre, J. C., Dupont, E., Jonas, K., Zagefka, H., \& Bourhis, R. (2003). Pictogram Immigrant Acculturation Scale for Children. Unpublished document.

Duckitt, J. (1992). The social psychology of prejudice. New York: Praeger.

Fazio, R. H., Powell, M. C., \& Herr, P. M. (1983). Toward a process model of the attitude-behavior relation: Accessing one's attitude upon mere observation of the attitude object. Journal of Personality and Social Psychology, 44, 723-735.

Festinger, L. (1957). A theory of cognitive dissonance. Stanford, CA: Stanford University Press.

Gaertner, S. L., \& Dovidio, J. F. (2000). Reducing intergroup bias: The common in-group identity model. New York: Psychology Press.

Gavin, L. A., \& Furman, W. (1989). Age differences in adolescents' perceptions of their peer groups. Developmental Psychology, 25, 827-834.

Glasberg, R., \& Aboud, F. E. (1981). A developmental perspective on the study of depression: Children's evaluative reactions to sadness. Developmental Psychology, 17, 195-202. 
Greenwald, A. G., McGhee, D. E., \& Schwartz, J. L. K. (1998). Measuring individual differences in implicit cognition: The Implicit Association Test. Journal of Personality and Social Psychology, 74, 1464-1480.

Hill, M. E., \& Augoustinos, M. (2001). Stereotype change and prejudice reduction: Short- and long-term evaluation of a cross-cultural awareness program. Journal of Community and Applied Social Psychology, 11, 243262.

Katz, P., \& Zalk, S. (1978). Modification of children's racial attitudes. Developmental Psychology, 14, 447-461.

Koeller, S. (1977). The effect of listening to excerpts from children's stories about Mexican-Americans on the attitudes of sixth graders. Journal of Educational Research, 70, 329-334.

Kent Refugee Action Network. (2006). Refugees in Kent today. Retrieved August 6, 2006, from www.kran.org.uk/kent.html

Lessing, E. E., \& Clarke, C. C. (1976). An attempt to reduce ethnic prejudice and assess its correlates in a junior high school sample. Educational Research Quarterly, 1, 3-16.

McGregor, J. (1993). Effectiveness of role-playing anti-racist teaching in reducing student prejudice. Journal of Educational Research, 86, 215-226.

National Statistics. (2006). Immigration statistics. Retrieved August 10, 2006, from www.homeoffice.gov.uk/rds/immigration 1.html

Neuberg, S. L. (1996). Expectancy influences in social interaction: The moderating role of social goals. In J. A. Bargh \& P. M. Gollwitzer (Eds.), The psychology of action: Linking cognition and motivation to behavior (pp. 529-552). New York: Guilford.

Paolini, S., Hewstone, M., Cairns, E., \& Voci, A. (2004). Effects of direct and indirect cross-group friendships on judgments of Catholic and Protestants in Northern Ireland: The mediating role of an anxiety-reduction mechanism. Personality and Social Psychology Bulletin, 30, 770-786.

Pettigrew, T. F. (1997). Generalized intergroup contact effects on prejudice. Personality and Social Psychology Bulletin, 23, 173-185.

Pettigrew, T. F. (1998). Intergroup contact theory. Annual Review of Psychology, 49, 65-85.

Pettigrew, T. F., \& Tropp, L. R. (2006). A meta-analytic test of intergroup contact theory. Journal of Personality and Social Psychology, 90, 751-783.

Piaget, J. (1970). Piaget's theory. In P. H. Mussen (Ed.), Carmichael's manual of child psychology (pp. 703-732.) New York: Wiley.

Rothbart, M., \& John, O. P. (1985). Social categorization and behavioral episodes: A cognitive analysis of the effects of intergroup contact. Journal of Social Issues, 41, 81-104.

Short, G., \& Carrington, B. (1996). Anti-racist education, multiculturalism, and the new racism. Educational Review, 48, 65-77. 
Slavin, R. E., \& Madden, N. A. (1979). School practices that improve race relations. American Educational Research Journal, 16, 169-180.

Sleeter, C. E., \& Grant, C. A. (1994). Making choices for multi-cultural education. New York: Macmillan.

Spencer, M. S. (1998). Reducing racism in schools: Moving beyond the rhetoric. Social Work in Education, 20, 25-36.

Stangor, C., Sullivan, L. A., \& Ford, T. E. (1991). Affective and cognitive determinants of prejudice. Social Cognition, 9, 359-380.

Stephan, W. G., \& Finlay, K. (1999). The role of empathy in improving intergroup relations. Journal of Social Issues, 55, 729-743.

Turner, R. N., Hewstone, M., Voci, A., \& Vonofakou, C. (in press). A test of the extended intergroup contact hypothesis: The mediating role of intergroup anxiety, perceived ingroup and outgroup norms, and inclusion of the outgroup in the self. Journal of Personality and Social Psychology.

Turner, R. N., Hewstone, M., Voci, A., Paolini, S., \& Christ, O. (2007). Reducing prejudice via direct and extended cross-group friendship. European Review of Social Psychology, 18, 212-255.

United Nations High Commissioner for Refugees. (2006). 2005 global refugee trends: Statistical overview of populations of refugees, asylum-seekers, internally displaced persons, stateless persons, and other persons of concern to UNHCR. Retrieved August 6, 2006, from www.unhcr.org/statistics

Van Oudenhoven, J. P., Prins, K. S., \& Buunk, B. P. (1998). Attitudes of minority and majority members towards adaptation of immigrants. European Journal of Social Psychology, 28, 995-1013.

Vrij, A., Akehurst, L., \& Smith, B. (2003). Reducing ethnic prejudice: An evaluation of seven recommended principles for incorporation in public campaigns. Journal of Community and Applied Social Psychology, 13, 284-299.

Walker, H. (1989). Towards anti-racist, multicultural practice with underfives. Early Child Development and Care, 41, 103-112.

Walker, I., \& Crogan, M. (1998). Academic performance, prejudice, and the jigsaw classroom: New pieces to the puzzle. Journal of Community and Applied Social Psychology, 8, 381-393.

Wright, S. C., Aron, A., McLaughlin-Volpe, T., \& Ropp, S. A. (1997). The extended contact effect: Knowledge of cross-group friendships and prejudice. Journal of Personality and Social Psychology, 73, 73-90.

Zagefka, H., \& Brown, R. (2002). The relationship between acculturation strategies, relative fit, and intergroup relations: Immigrant-majority relations in Germany. European Journal of Social Psychology, 32, 171-188.

Zick, A., Wagner, U., van Dick, R., \& Petzel, T. (2001). Acculturation and prejudice in Germany: Majority and minority perspectives. Journal of Social Issues, 57, 541-557. 


\section{Appendix}

Pictorial Measure: Preferred Acculturation Strategy and Perceived Acculturation Strategy of Refugees

Imagine that a refugee who is exactly like an English person looks like this:

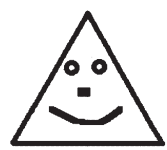

Imagine that a refugee who is just the same as they were in their home country looks like this:

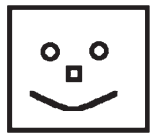

1. Do YOU think refugees should...?

STAY LIKE THEY

BE JUST LIKE

ARE IN

THEIR HOME

AN ENGLISH

COUNTRY?
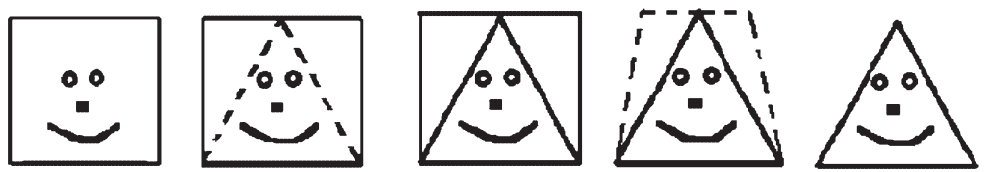

Circle the one that shows what you think the most.

2. Now what do you think REFUGEES would want to do?

STAY LIKE THEY

ARE IN

THEIR HOME

COUNTRY?
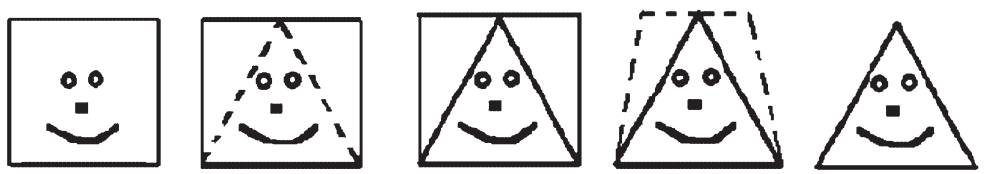

Circle the one that shows what you think they want the most.
AN ENGLISH

PERSON? 